\title{
Gathering In Coal Mines
}

\author{
BY R. L. KINGSLAND \\ Consolidation Coal Company, Inc., Fairmont, W. Va.
}

$I^{1}$ $T$ was evidently the intention of your Committee that this paper should deal principally with a comparison of costs for different methods of gathering. One case, cited from records of the Consolidation Coal Company, will show that such comparisons are hardly practical. During 1916 coal was gathered for 5 cents per car. During 1920 coal was gathered with the same locomotive, from the same mines, and under mining conditions more favorable to the locomotives, for 20 cents per car. This increase is accounted for by large labor increase, poor and irregular railroad car supply, and decrease in efficiency of labor.

The above case shows the wide variation in costs due to changing conditions other than mining conditions. The different conditions encountered in different mines may give as wide variation in costs as the one above.

As costs for the past few years have not been comparable, and also as I do not have sufficient comparable figures for different methods of gathering under similar conditions for any one period, it will be necessary to confine this paper to a discussion of the different methods available for gathering coal and a short discussion of the limitations of each.

- The simplest form of gathering is where the miners themselves push the cars into and out of the rooms. Obviously this method has great limitations, but it is still being employed in some places where the grades are in favor of the loads and where small cars are used.

Horses or mules probably still gather the greatest part of coal mined in the bituminous fields. Our experience has shown that a fair average for live stock gathering is two and one-half cars per hour or twenty cars for an eight-hour day.

We now come to mechanical gathering. This is a comparatively new field and I believe should be approached by the average mine operator with considerable caution. It is the writer's opinion that the cases where a decrease in gathering cost can be made, due to changing from live stock to mechanical gathering, are the exception, rather than the general rule. By this I do not mean to say that mechanical gathering does not have an important part to play in the coal mining of today. There are other reasons, aside from costs, which will justify replacing stock gathering with mechanical gathering: Such as, scarcity of labor, the attitude of labor against pushing any cars, and the fact that increased tonnage can be had from some mines due to less congestion in traffic with mechanical gathering.

Presented at the combined meeting of the Pittshurgh Sections of the A.I.E.E. and A.I. M. E., Pittsburgh, Pa., January 21,1921 .
The only power that we have used for gathering locomotives has been electric power, so I limit myself to electrically driven locomotives. Of these there are three principal types: ( rab reel, cable reel, and storage battery locomotives. We have found that good results could not be obtained from the straight crab reel locomotive due to the excessive amount of labor required in pulling the cable into the rooms. Also this type of locomotive is not suited to pushing empty cars into the room. We have found, however, that in some mines, crab reels on part of our locomotives are very handy for odd jobs.

Cable reel locomotives, we consider as one of the most adaptable types for gathering. These locomotives are very flexible and have been successfully run with some very long cables. The principal trouble that we know of with them, is cable trouble. Inexperienced motormen will run over their cable frequently and cause considerable delay.

The third principal type is the straight storage battery locomotive. This locomotive has maximum flexibility as it can run anywhere, irrespective of feed lines and return lines, on its own power. There are, however, several limitations to the battery locomotive. It is limited in its day's work by the size of battery and the corresponding amount of energy which can be stored in same. Due to the weight of the battery, the locomotive can be abused by pulling too large trips, under which condition the battery energy will be expanded before the end of the day. The batteries require expert and systematic attention.

Our company has had considerable experience with combination trolley and storage hattery locomotives. About 50 of these have been installed in one of our divisions. These are standard 250-volt, two-motor, six-ton locomotives, of the type usually used with cable reels. We have dispensed with cable reels and provided the locomotives with storage batteries in their place. The batteries receive boosting charges throughout the day, whenever the locomotives are running on trolley. The special field for this locomotive is where the mining work is scattered. The locomotive can gather a few cars in one place on the battery, and then run, on the trolley, to some other section for a few more cars. In comparison with the reel locomotives our mine people claim that it has extra flexibility. In comparison with the straight storage battery locomotives it has a much wider range of operation, due to its high speed on the trolley and the extra drawbar pull, which it is capable of exerting while on the trolley.

No mention has been made so far of room hoists. We have found it necessary to use these in some parts of our mines where the grades are too heavy for loco- 
motives. As a general rule I would say that grades averaging 15 per cent are about as steep as can be successfully met with locomotives. We, of course, realize that locomotives have been, and are being, used on grades considerable in excess of this. The maximum grade on which I have seen a locomotive operate was 25 per cent.

The big question for the mining man is to know what type of locomotive to apply to the individual mine which he has under consideration. There are some mines where this question is very simple, but the majority of them will permit the installation of two or more types of locomotives and it is extremely difficult to determine which type will give the maximum results.

Let us assume as an average condition a mine that is at present gathering with live stock. The chances are that the mine will be developed so that in the majority of cases the grades will be in favor of the load. Part of the empty cars are delivered to the face with live stock and probably part of them are pushed from the room necks to the face by men. Also part of the loads are pulled from the face with live stock and the remainder are dropped from the face to the room necks by the men. In practically all cases the loads are not taken farther than the end of the room entry by the live stock. In most cases rooms are driven only one way from the room entry, and there are probably not more than six or eight rooms being worked on each entry. Under these conditions the live stock will average about 20 cars a day per head. In changing over to mechanical gathering, in order to make a favorable showing it would be necessary for each locomotive to replace four head of live stock. This would mean that two men with one locomotive would do the work of four men with four head of stock. It should be understood from the beginning that this result cannot be accomplished unless changes are made in the method of mining and condition of mine tracks. We have found in all cases where this change in the method of gathering has been made that it is necessary to improve materially track conditions so as to prevent derailment. Also the development work in the mines should be laid out so that each locomotive can get its full quota of loads from one room entry if possible, and in no case more than two room entries. Another important point is to avoid increasing the length of haul from the working faces to the side tracks in changing the gathering system. The tendency with most mine superintendents is to believe that the gathering locomotives should be able to haul farther than the stock, and they therefore expect them not only to gather as much as four head of stock but to haul these cars a greater distance to a side track than the live stock had previously done. All of the points mentioned above seem simple, but we have found by experience that they are quite important.

We will now turn to the special application of differ- ent types of locomotives. One undisputed field for the straight storage battery locomotive is in gaseous mines where no other type of locomotive is permissible. On the other hand, where heavy grades against the loads are encountered, the straight storage battery locomotive is not practical, as sufficient energy cannot be stored in it for the day's work. Between these two limitations there is left by far the biggest field where the different types of gathering locomotives meet on nearly equal grounds. Before leaving the battery locomotive I strongly advise against the installation of any such type of locomotives unless a sufficient number of them are installed so that they are accessible enough for a trained battery man to give each one regular and systematic inspection. Under general conditions I do not believe that it is advisable for an isolated mine to install one or two battery locomotives, unless it happens to have a man familiar with such equipment who will give them the necessary supervision. My strongest argument in support of this recommendation is the fact that we have been able to operate lead batteries in combination lucomotives under the above recommended plan so that we have secured an average of about 50 per cent more than the guaranteed life on same. It should be noted that the service in combination locomotives is even more severe than that in straight storage battery locomotives, in so far as the batteries are concerned. This is due to the fact that in straight storage battery locomotives there are only one charge and one discharge per shift, while with combination locomotives the battery starts the day fully charged and is given boosting charges at frequent intervals throughout the day. This probably averages the equal of at least two full charges and two full discharges per shift, or twice the service demanded from straight battery locomotives.

In the case of a new mine that will be developed so that the work will be concentrated and each locomotive can get its full quota of coal from one or two room entries, and where the grades are not prohibitive, I would recommend the straight storage battery locomotive as being best suited for the work.

We still have left the majority of applications for gathering locomotives; that is, for operating mines that wish to install mechanical gathering. We have only eliminated from these mines, those that are gaseous, and those that have grades averaging 15 per cent or more. For the remaining mines consider that the straight storage battery locomotive has the smallest application. It should be applied to mines where the work is already concentrated, to those where the large part of the work will be concentrated within a short time, and to those where the maximum average grade is under 5 per cent.

There are now left the reel and the combination locomotives. I would recommend the reel locomotive for maximum average grades up to 15 per cent, and 
the combination locomotive for maximum average grades up to 10 per cent. The latter limitation is made on account of the limited energy storage capacity of the storage battery. We have already given limitations which recommend against the use of storage batteries unless a sufficient number of them are installed close enough together for one battery man to keep close track of their care and operation. For the cases where there are not enough batteries to justify the services of one man for their care, I would recommend the cable reel locomotives. For the cases where there are a sufficient number of locomotives to justify the services of a battery man, I would recommend the combination locomotives. This recommendation is based on experience with both types of locomotives. The combination locomotives have been found more flexible, due to their lower speed and closer speed regulation when running from the battery. The battery should give about 125 volts while the reels have full trolley voltage of 250 or 500 volts. Also experience has shown that there are less delays due to batteries and accessories than due to cable reels and accessories. A locomotive with cable reels costs less than the same locomotive with storage batteries. I have found that the maintenance cost on one is about the same as that on the other. There is probably some small difference in power consumption of the two types. We have not made any accurate tests on this, because general results show that there is no appreciable difference. Our records show that the combination locomotive will gather from three to five cars more than the reel type per day, and we consider that this increase more than makes up for the extra investment

\section{TELEPHONE PROGRESS IN CHINA}

A movement has been inaugurated to hunt up all the principal cities of China by long-distance telephone toll lines. This movement started with the business men of northern China who realize that little progress will be made in the unification of the country until modern methods of communication are adopted. The telephone is especially adapted to conditions in China, because the use of the telegraph is beset with many difficulties on account of the many characters in the Chinese alphabet which make it necessary to send all messages in code.

It is reported by Mr. Clark H. Minor, former Manager of the China Electric Co., of Pekin, who has just arrived in New York, that work has already begun on a long distance line between Shanghai and Peking that will connect with the toll system now in operation between the northern capital and Tietsin. The latter line, which has the distinction of being the only inter-city cable now existent in China, is only 100 miles long. The new line probably will be completed late this year. It will cost about $\$ 500,000$ and will be constructed according to American standards.

New exchanges are also being erected m most of the larger cities to augment the 55,000 subscriber lines necessary for the combination trolley and storage battery locomotive.

So far no mention has been made of mechanical gathering other than locomotive gathering and room hoists. Numerous systems of conveyers and scraper loaders have been suggested, but to date we have not found any that we could apply to our systems of mining so as to show a saving over locomotive gathering, nor have we seen our way clear to change our systems so as to suit any of the methods suggested.

When considering mechanical gathering for a mine, too much emphasis cannot be placed on the necessity of making mining conditions suitable for such gathering. For a new mine, where mechanical gathering will be used from the start, this should cause but little extra expense. For an old mine where live stock has been used extreme care must be taken in selecting the best method of mechanical gathering for the individual mine, all tracks must be put in good shape, the feed lines and returns must be ample for the service and ample side tracks must be provided as close as practical to the working faces. Also the more the mine workings are concentrated the better will be the results with mechanical gathering. Unless all of these things are watched closely the cost of mechanical gathering will show an increase over live stock gathering. With mechanical gathering the weight of locomotive can be suited to the weight of the cars. Under given conditions a locomotive should gather a certain number of cars per day. The larger the cars the larger the locomotive, but the number of cars gathered per day remains practically constant. Obviously the larger the car the cheaper the gathering cost per ton of coal mined.

already in use in China. Girls are being trained for operators in Shanghai for the first time. It is also probable that girls will be used in the operation of the new system in the Yangtse valley. Hitherto due to the cheapness of male labor all work at the Chinese exchanges has been done by men. It is expected that it will require ten years to give China the telephone service its more active citizens desire.

\section{ELECTRIFICATION OF JAPANESE RAILWAYS}

The official system for the electrification of the railways of Japan has recently been revised and a new electric bureau established, states an issue of the Yokohama Chamber of Commerce Journal. According to the plan now being worked out by the Department of Railways, the first steps will be to electrify the entire Tokaido line, whose traffic has been increasing enormously each year, from Tokyo to Kobe, and a part of the Central line between Iidamachi station in Tokyo and Kofu, in the rear of Mount Fuji, where many tunnels make transportation slow. Electric trains will be used exclusively for passengers, freight trains being propelled by steam as at present. 